\title{
Effect of intercropping on leaf senescence related to physiological metabolism in proso millet (Panicum miliaceum L.)
}

\author{
X.W. GONG ${ }^{*, * *, \dagger}$, C.J. LIU ${ }^{* * *, \dagger}$, U. FERDINAND ${ }^{*, * *}$, K. DANG $^{*, * *}$, G. ZHAO ${ }^{*, * *}$, P. YANG $^{*, * *}$, \\ and B.L. FENG ${ }^{* * *,+}$ \\ College of Agronomy, State Key Laboratory of Crop Stress Biology in Arid Areas/Northwest A \& F University, \\ Yangling, 712100 Shaanxi, China* \\ Shaanxi Research Station of Crop Gene Resources \& Germplasm Enhancement, Ministry of Agriculture, \\ 712100 Shaanxi, China** \\ College of Life Sciences/Northwest A \& F University, Yangling, 712100 Shaanxi, China ${ }^{* * *}$
}

\begin{abstract}
The field experiments were conducted to explore the changes in metabolism related to leaf senescence in proso millet (Panicum miliaceum L.) under proso millet/mung bean intercropping system. Results showed that intercropping increased leaf photosynthesis, as measured by the increased net photosynthetic rate and chlorophyll content, maximum photochemical efficiency of PSII, and decreased nonphotochemical quenching coefficient. These responses resulted in the increased leaf number and area and reduced yellowing leaf rate; leaf photosynthetic capacity was maintained for longer periods. Such improvements occurred due to enhanced activities of protective enzymes (superoxide dismutase, catalase, peroxidase) and lowered malondialdehyde and superoxide radical contents. This conclusion was supported by the increased $\mathrm{N}$ metabolism in leaves. The grain yield was stimulated by $6.8-37.3 \%$ compared to the sole system. Intercropping patterns would delay proso millet leaf senescence and increase grain yield in this region.
\end{abstract}

Additional key words: antioxidant system; chlorophyll $a$ fluorescence; gas exchange; glutamine synthetase; leaf area; nitrate reductase.

\section{Introduction}

Senescence, which is a complex physiological process, can trigger various plant responses from gene expression patterns to physiological metabolism, plant growth, and development, thereby leading to decreased productivity of agricultural crops (Fang and Xiong 2015). Generally, leaf area duration and green leaf area proportionally affect the grain yield by regulating the ratio of assimilate supply (i.e., source) to demand (i.e., sink) (Feller et al. 2008). The most obvious biological property of leaf senescence is that the leaf turns yellow secondary to chlorophyll (Chl) degradation (Fang et al. 1998). Chl degradation may occur due to oxidative stress developed in chloroplasts, which is one of the main generators of reactive oxygen species (ROS). ROS are highly reactive and can severely damage cell structures and cellular components (Djanaguiraman et al. 2009). During the Chl degradation, further production of malondialdehyde (MDA) negatively affects grain filling, remobilization of nutrients, degradation of $\mathrm{Chl}$-protein complexes, and lipid peroxidation (Frank and Dat 2006, Gill and Tuteja 2010). In contrast, a scavenging system comprising antioxidants, such as superoxide dismutase (SOD), catalase (CAT), and peroxide (POD), can reduce cellular damage caused by ROS and delay leaf senescence (Khatun et al. 2008). Therefore, leaf senescence should be correlated closely with antioxidant metabolism; furthermore, strategies protecting the leaf from oxidative damage and delaying senescence are essential for improving the antioxidative defense system (Navabpour et al. 2003).

A relationship between crop productivity and leaf senescence has been postulated for many years (Zhang and Zhou 2013). Many reports have demonstrated that delaying leaf senescence can be associated with cropping pattern and cultivation system under field conditions (Jiang et al.

Received 16 March 2019, accepted 16 July 2019.

${ }^{+}$Corresponding author; phone: +86-29-87082889, fax: +86-29-87082889, e-mail: 7012766@163.com

Abbreviations: ASA - reduced ascorbic acid; CAT - catalase; Chl - chlorophyll; FAA - free amino acid; $\mathrm{F}_{\mathrm{v}} / \mathrm{F}_{\mathrm{m}}-$ maximal quantum yield of PSII photochemistry; $g_{\mathrm{s}}$ - stomatal conductance; GS - glutamine synthetase; LA - leaf area; LN - leaf number; MDA malondialdehyde; NPQ - nonphotochemical quenching coefficient; NR - nitrate reductase; $\mathrm{O}_{2}{ }^{-}-$superoxide radical; $P_{\mathrm{N}}-$ net photosynthetic rate; POD - peroxidase; $\mathrm{q}_{\mathrm{L}}$ - photochemical quenching coefficient; SOD - superoxide dismutase; SP - soluble protein; YLR - yellow leaf rate; $\Phi_{\text {PSII }}$ - quantum yield of PSII.

Acknowledgments: The research was supported by the National Millet Crops Research and Development System (CARS-06-13.5-A26), National Natural Science Foundation of China (31371529), National Science and Technology Supporting Plan (2014BAD07B03), and Minor Grain Crops Research and Development System of Shaanxi Province (2009-2018).

†These authors contributed equally to this work. 
2004, Špundová et al. 2005). Ali et al. (2018) found that ridge-furrow mulched with plastic film cultivation system achieved increased net photosynthetic rates $\left(P_{\mathrm{N}}\right)$ and grain yield in winter wheat, and this effect was attributed to reduced MDA content and oxidative damage, which regulated leaf senescence. Ren et al. (2018) discussed that the exogenous application of 6-benzyladenine effectively alleviated adverse effects of waterlogging on the carbon metabolism of summer maize and damage on antioxidative enzyme activity, thereby delaying leaf senescence and resulting in substantial increase in grain yield. Reasonable cultivation measures are important in delaying leaf senescence and increasing yield.

Intercropping with two crop species on the same area of land is an important strategy in developing sustainable production systems, particularly systems that aim to limit external inputs (Willey 1979). Compared to monoculture cropping system, the intercropping system greatly contributes to crop production through the effective utilization of resources, such as water, nutrients, land, solar radiation, and atmospheric $\mathrm{CO}_{2}$ (Inal et al. 2007, Liu et al. 2017). Intercropping system can improve plant productivity and ecological benefits (Naudin et al. 2014). However, little information is available regarding the changes in physiological metabolism of minor grain crops under intercropping patterns. Proso millet (Panicum miliaceum L.), which originated from China approximately 10,000 years ago, is planted as a source of staple food and fodder in the semiarid regions of China due to its high nutritional value (Yang et al. 2018) and high resistance to drought, high temperature, and poor soil conditions (Zhang et al. 2017). As a $\mathrm{C}_{4}$ plant, physiological processes mainly occur in the leaves of proso millet, especially antioxidant metabolism. It is therefore important to study the influences of intercropping on the leaf senescence in proso millet. We hypothesized that intercropping would increase yield by regulating the physiological metabolism and delaying leaf senescence in proso millet. Thus, this study aimed to (1) indicate the influence of intercropping on proso millet senescence and biomass accumulation, such as leaf number and yellow leaf rate, and finally improve yield; (2) investigate the changes in the photosynthetic and Chl fluorescence parameters under intercropping conditions; and (3) explore the effects of intercropping on the contents of superoxide radicals and MDA and the activities of antioxidant enzymes (SOD, CAT, and POD) involved in scavenging ROS. Subsequently, the changes in nitrogen metabolism of leaves would prove our hypothesis.

\section{Materials and methods}

Experiments and location: Field experiments were established at the Minor Grain Experimental Station of Northwest A\&F University, Yulin, China $\left(37^{\circ} 56^{\prime} 26^{\prime \prime} \mathrm{N}\right.$, $109^{\circ} 21^{\prime} 46^{\prime \prime} \mathrm{E} ; 1,120 \mathrm{~m}$ a.s.1.) in 2017 and 2018. The location has a temperate semiarid continental monsoon climate, an average annual temperature of $8.3^{\circ} \mathrm{C}$, and annual mean precipitation of approximately $395 \mathrm{~mm}$, which mainly happens during the growing season of proso millet from June to September. The precipitation $(\mathrm{mm})$ and mean air temperature $\left({ }^{\circ} \mathrm{C}\right)$ during the two studied years of the proso millet growing season are presented in Fig. 1S (supplement). The growing season in 2018 was wetter than that in 2017, particularly in July and August. The different precipitations were expected to affect the growth and yield of proso millet in the two experimental seasons. The temperatures did not remarkably change in both years. The experimental soil had a loess-like loam texture of $\mathrm{pH}$ 8.6. Before sowing, the soil $(0-20 \mathrm{~cm})$ contained 7.3 and $7.6 \mathrm{~g}$ (organic matter) $\mathrm{kg}^{-1}, 0.29$ and $0.32 \mathrm{~g}$ (total $\mathrm{N}$ ) $\mathrm{kg}^{-1}$, 26.6 and $29.4 \mathrm{mg}$ (available $\mathrm{P}) \mathrm{kg}^{-1}$, and 221.5 and $235.2 \mathrm{mg}$ (available K) $\mathrm{kg}^{-1}$ in 2017 and 2018, respectively.

Experimental design and treatments: The experiment was arranged in a randomized complete block design with three replications. Proso millet cultivar 'Shanmi-1' and mung bean cultivar 'Zhonglv- 8 ' adapted to the local conditions were selected. The treatments were as follows: (1) two rows of proso millet alternated with two rows of mung bean (2M2B); (2) four rows of proso millet alternated with two rows of mung bean (4M2B); (3) four rows of proso millet alternated with four rows of mung bean (4M4B); and (4) two rows of proso millet alternated with four rows of mung bean (2M4B). The sole proso millet (SM) and mung bean (SB) were set as control. Two crops were planted in a north-south row direction. Fig. $2 \mathrm{~S}$ (supplement) shows the schematic diagram of the different intercropping patterns. All in-row space distances were $0.33 \mathrm{~m}$, including those between adjacent proso millet and mung bean and between two adjacent proso millet plants and two adjacent mung bean plants in a row. Each experimental plot had an area of $30 \mathrm{~m}^{2}(6 \times 5 \mathrm{~m})$, including three-strip proso millet and mung bean.

Proso millet was sown on 12 June 2017 and 10 June 2018 and harvested on 23 September 2017 and 25 September 2014. Mung bean was sown on 28 May 2017 and 18 May 2018 and harvested on 24 August 2017 and 20 August 2018. The plant densities of proso millet and mung bean for both sole crops and intercrops were 50 and 20 plants $\mathrm{m}^{-2}$, respectively. Basal fertilizers $\left[120 \mathrm{~kg}(\mathrm{~N}) \mathrm{ha}^{-1}\right.$, $100 \mathrm{~kg}\left(\mathrm{P}_{2} \mathrm{O}_{5}\right) \mathrm{ha}^{-1}$, and $\left.75 \mathrm{~kg}\left(\mathrm{~K}_{2} \mathrm{O}\right) \mathrm{ha}^{-1}\right]$ were applied to the soils before planting each year. During the growth period, fertilizers were not applied, and weeds and insects were effectively controlled.

Photosynthetic and Chl fluorescence parameters: Photosynthetic parameters [net photosynthetic rate $\left(P_{\mathrm{N}}\right)$, stomatal conductance $\left.\left(g_{\mathrm{s}}\right)\right]$ were measured on the functional uppermost fully developed flag leaves of the plant between 9:00-11:00 h at the flowering, filling, and maturity stage by using a portable photosynthesis system $\mathrm{Li}-6400$ ( $\mathrm{Li}$-COR, Lincoln, NE, USA) at $1,200 \mathrm{~mol}$ (photon) $\mathrm{m}^{-2} \mathrm{~s}^{-1}$, leaf temperature of $30^{\circ} \mathrm{C}, \mathrm{CO}_{2}$ concentration of $300 \mathrm{~mol} \mathrm{~mol}^{-1}$, and relative humidity of $60 \%$ in 2017 and 2018. Five plants per treatment were randomly selected for measuring photosynthesis.

Total Chl was extracted from frozen flag leaf samples $(0.2 \mathrm{~g})$ with $80 \%(\mathrm{v} / \mathrm{v})$ acetone. After centrifugation, the extract was subjected to spectrophotometric measurements (UV-2550, Shimadzu, Japan) at 645 and $663 \mathrm{~nm}$. The 
Chl $a$ and $b$ concentrations were calculated by using the Lichtenthaler (1987) formula. Total Chl concentration $\left[\mathrm{mg} \mathrm{g}^{-1}\right.$ (fresh mass, FM)] and $\mathrm{Chl} a / b$ ratio were calculated. Five plant samples were analyzed per treatment.

At the same time, Chl fluorescence parameters of the same leaves were measured by using a MINI-PAM-II fluorometer (Imaging PAM, Walz, Effeltrich, Germany) in 2017 and 2018. The maximal quantum yield of PSII photochemistry $\left(\mathrm{F}_{\mathrm{v}} / \mathrm{F}_{\mathrm{m}}\right)$ was measured after a 30-min period of dark adaptation. Five plants were analyzed per treatment. The photochemical quenching coefficient $\left(\mathrm{q}_{\mathrm{L}}\right)$ and nonphotochemical quenching coefficient (NPQ) were calculated based on the dark- and light-adapted fluorescence measurements. The actual PSII efficiency $\left(\Phi_{\mathrm{PSII}}\right)$ was calculated as $\Phi_{\text {PSII }}=\mathrm{F}_{\mathrm{v}} / \mathrm{F}_{\mathrm{m}} \times \mathrm{q}_{\mathrm{P}}$ according to Maxwell and Johnson (2000).

Antioxidant metabolism: Frozen flag leaf tissue $(0.2 \mathrm{~g})$ was crushed in $5 \mathrm{~mL}$ of $0.1 \mathrm{M}$ Tris- $\mathrm{HCl}$ buffer at $\mathrm{pH} 7.8$ containing $1 \mathrm{mM}$ dithiothreitol, $1 \mathrm{mM}$ EDTA, and $1 \%$ polyvinyl pyrrolidone. The homogenate was centrifuged at $20,000 \times \mathrm{g}$ for $20 \mathrm{~min}$ at $4^{\circ} \mathrm{C}$. The clear supernatant was used for measuring the enzyme activities.

Superoxide dismutase (SOD, EC 1.15.1.1) activity was assayed by monitoring the inhibition of photochemical reduction of nitroblue tetrazolium, as described by Lei et al. (2006). Peroxidase (POD, EC 1.11.1.7) activity was estimated as the decomposition rate of $\mathrm{H}_{2} \mathrm{O}_{2}$ by POD with guaiacol as hydrogen donor by measuring the change rate of absorbance at $436 \mathrm{~nm}$ (Lin and Kao 1999). Catalase (CAT, EC 1.11.1.6) was assayed according to Djanaguiraman et al. (2009) by potassium permanganate titration and expressed as $\mu \mathrm{M}\left(\mathrm{H}_{2} \mathrm{O}_{2}\right) \mathrm{g}^{-1}(\mathrm{FM}) \mathrm{min}^{-1}$. MDA was determined according to Zhao et al. (2013) with some modification and was calculated using the following formula: $\mathrm{MDA}\left[\mathrm{mg} \mathrm{g}^{-1}\right]=6.45 \times\left(\mathrm{OD}_{532}-\mathrm{OD}_{600}\right)-$ $0.56 \times \mathrm{OD}_{450}$. MDA content was expressed in $\mathrm{mg} \mathrm{g}^{-1}(\mathrm{FM})$. Superoxide radical $\left(\mathrm{O}_{2}{ }^{--}\right)$content was measured as described by Elstner and Heupel (1976) by using the hydroxylamine oxidation method. Reduced ascorbic acid (ASA) was estimated according to the methods of Hodges et al. (1996) with some modifications.

Physiological metabolism: Glutamine synthetase (GS, EC 1.6.6.1) activity was extracted as previously described (Kaiser and Lewis 1984) with slight modification. Frozen flag leaves $(0.3 \mathrm{~g})$ were cut into small pieces, fully ground in liquid nitrogen, and extracted in $1 \mathrm{~mL}$ of Tris- $\mathrm{HCl}$ (pH 7.8) containing $1 \mathrm{mM}$ EDTA, 15\% glycerol, $14 \mathrm{mM}$ 2-mercaptoethanol, and $0.1 \%$ Triton $X$-100. The homogenate was centrifuged at $12,000 \times g$ for $10 \mathrm{~min}$. Enzyme activity was determined by measuring the formation of glutamyl hydroxamate in the supernatant at $540 \mathrm{~nm}$ after reaction with acidified ferric chloride. Nitrate reductase (NR, EC 1.6.6.1) activity was measured as described by Ding et al. (2006). Frozen flag leaf tissue (0.3 g) was ground with $4 \mathrm{~mL}$ of $0.1 \mathrm{M}$ phosphate buffer $(\mathrm{pH} 7.5)$ prepared by mixing $\mathrm{NaH}_{2} \mathrm{PO}_{4} \cdot 2 \mathrm{H}_{2} \mathrm{O}$ and $\mathrm{Na}_{2} \mathrm{HPO}_{4} \cdot 12 \mathrm{H}_{2} \mathrm{O}$ and then centrifuged at $12,000 \times \mathrm{g}$ for $20 \mathrm{~min}$ at $4^{\circ} \mathrm{C}$. The reaction mixture contained $0.4 \mathrm{~mL}$ of NADH, $1.2 \mathrm{~mL}$ of $0.1 \mathrm{M} \mathrm{KNO}_{3}$, and $0.4 \mathrm{~mL}$ of extraction solution. The mixtures were incubated at $25^{\circ} \mathrm{C}$ for $30 \mathrm{~min}$. The control solution without $\mathrm{NADH}$ was replaced with $0.4 \mathrm{~mL}$ of $0.1 \mathrm{M}$ sodium phosphate $(\mathrm{pH} 7.5)$. The reaction was stopped by using $1 \mathrm{~mL}$ of sulfanilamide. Afterward, $1 \mathrm{~mL}$ of $1 \%$ N-1-naphthylethylenediamine dihydrochloride was added. The red color should be developed for $15 \mathrm{~min}$ before centrifugation at $12,000 \times g$ for $10 \mathrm{~min}$. Absorbance at $540 \mathrm{~nm}$ was determined by using an spectrophotometer (UV-2550, Shimadzu, Japan). Soluble protein content was determined by using Bradford's method (1976). Frozen leaf $(0.3 \mathrm{~g})$ was used for the extraction, and $0.1 \mathrm{~mL}$ of extract was pipetted into a test tube. Afterwards, $5 \mathrm{~mL}$ of Coomassie Brilliant Blue G-250 solution was added to the test tubes before vortex mixing. The absorbance at $595 \mathrm{~nm}$ was measured. Bovine serum albumin was used to prepare the standard curve. The free amino acid content was assayed according to the ninhydrin method ( $\mathrm{Hu}$ et al. 2018) with slight modification. The sample was crushed in $5 \mathrm{~mL}$ of cold phosphate buffer (50 mM KH $\mathrm{PO}_{4}, \mathrm{pH} 7$ ), and centrifuged at $12,000 \times \mathrm{g}$ for $15 \mathrm{~min}$. The supernatant was used for analysis. Exactly $1.5 \mathrm{~mL}$ of the extract was added into a tube before adding $0.5 \mathrm{~mL}$ of $3 \%(\mathrm{w} / \mathrm{v})$ ninhydrin in $95 \%(\mathrm{v} / \mathrm{v})$ ethanol. The samples were heated at $100^{\circ} \mathrm{C}$ for $10 \mathrm{~min}$ before adding $5 \mathrm{~mL}$ of $95 \%(\mathrm{v} / \mathrm{v})$ ethanol. The absorbance was detected at $570 \mathrm{~nm}$, and the free amino acid content was expressed as $\mathrm{mg} \mathrm{g}^{-1}(\mathrm{FM})$.

Biomass accumulation and partitioning: Proso millet samples were collected at the grain-filling stage in 2017 and 2018, respectively. On each sampling occasion, five similar plants in the same row were selected randomly and cut at the ground level. Proso millet samples were separated into the stem, leaf, sheath, and spike per plant and exposed at $105^{\circ} \mathrm{C}$ for $30 \mathrm{~min}$ to deactivate the enzymes, followed by continuous drying at a constant temperature of $80^{\circ} \mathrm{C}$ until constant mass was reached, at which time biomass was recorded.

Total leaf number was measured on five plants for each plot at the grain-filling stage, and total yellow leaf (more than two-thirds of the leaf area was yellow or brown) area were measured on three plants for each plot by using a $Y M J-C$ leaf area meter (Zhejiang, China). By using software analysis, the leaf area was obtained by taking pictures of the leaves on a whiteboard. Yellow leaf rate was calculated as described by $\mathrm{Hu}$ et al. (2016).

Grain yield and yield components: A total of ten plants in each plot were selected randomly to investigate the spike length, spike number per plant, and 1,000-grain mass of proso millet, and branch number per plant, pod number per plant, and 100-grain mass at harvest, respectively. Spike length refers to the distance from the bottom base to the top of the spikes, and 1,000-grain mass (100-grain mass) was determined by measuring the mass of 1,000 (100) seeds from each plot. For grain yield and 1,000-grain mass (100-grain mass), seeds were air-dried for two or three weeks, and seed water content was approximately $12 \%$ before measurement. 
Land equivalent ratio (LER) was used as an indicator of land productivity for the intensification of the evaluated alternatives and was obtained as follows (Li et al. 1999): $\mathrm{LER}=\left(\mathrm{Y}_{\mathrm{im}} / \mathrm{Y}_{\mathrm{sm}}\right)+\left(\mathrm{Y}_{\mathrm{ib}} / \mathrm{Y}_{\mathrm{sb}}\right)$, where $\mathrm{Y}_{\mathrm{sm}}$ and $\mathrm{Y}_{\mathrm{im}}$ are the sole and intercropped proso millet yields, respectively, and $\mathrm{Y}_{\mathrm{sb}}$ and $Y_{\mathrm{ib}}$ are the sole and intercropped mung bean yields, respectively. LER $>1$ signifies that the intensification alternative is more productive than the sum of the sole crops of its component species.

Statistical analysis: The data were consistent over years, but the results for each year were analyzed separately. Data were analyzed by using SPSS (version 19.0 for Windows, SPSS, Chicago, USA). The difference between mean values was determined by using least significant difference $(P=0.05)$ as indicated by different letters.

\section{Results}

Grain yield, yield components, and LER: Yield and components of proso millet and mung bean under relay intercropping and sole conditions are shown in Table 1. The grain yield components were remarkably affected by different row configurations, and all indices in the table were changed with different levels compared with the sole ones. The grain yields of proso millet in $2 \mathrm{M} 2 \mathrm{~B}, 4 \mathrm{M} 2 \mathrm{~B}$, 4M4B, and 2M4B were improved by $17.1,6.8,20.1$, and $37.3 \%$, respectively, compared with the sole system in the two seasons. In contrast, intercropping significantly decreased the grain yield and yield components of mung bean. Two years' data showed that the branch number per plant, pod number per plant, grain mass per plant and 100-grain mass of mung bean decreased by 18.9$37.7,16.7-39.4$, 33.6-54.1, and 3.8-9.4\%, respectively. The grain yield further was lower with different levels compared with that in the sole mung bean.

In general, the LER for the different intercropping patterns was all greater than unity $(>1)$, indicating that the cropping system used less land but produced more grain than their corresponding soles (Table 1). The maximum LER was 1.86 for 2017 and 2.22 for 2018 under 2P4M treatment, whereas the minimum LER was 1.50 for 2017 and 1.71 for 2018 under $4 \mathrm{P} 2 \mathrm{M}$ treatment, suggesting that adding mung bean rows or reducing proso millet rows was beneficial for boosting the productive use of land.

Plant senescence and biomass accumulation: Intercropping patterns markedly restrained plant senescence for both years (Table 2). Leaf number and area under intercropping systems were higher than those in the sole system, which increased by $10.1-62.8 \%$ and $4.3-41.7 \%$, respectively. Conversely, yellow leaf rates were markedly reduced by $32.3,19.0,37.0$, and $64.9 \%$ under $2 \mathrm{M} 2 \mathrm{~B}, 4 \mathrm{M} 2 \mathrm{~B}, 4 \mathrm{M} 4 \mathrm{~B}$, and 2M4B treatments, respectively, compared with the treatment of the sole proso millet. Moreover, intercropping patterns resulted in significant alterations in biomass accumulation. The biomass values of stem, leaf, sheath, and spike increased at different levels compared with those in the sole proso millet, and 2M4B treatment reached the maximum plant biomass among the intercropping patterns, which was $95.1,60.8,65.5$, and $99.5 \%$ higher, respectively.

Photosynthesis and $\mathbf{C h l}$ fluorescence parameters: Leaf senescence is related to the photosynthetic capacity and Chl. In this study, with the advanced growth period, the photosynthesis and $\mathrm{Chl}$ contents of leaf showed declining trends after flowering. The average $P_{\mathrm{N}}$ (Fig. 1A) and $g_{\mathrm{s}}$ (Fig. $1 B$ ) were considerably higher under intercropping patterns relative to the sole proso millet, which increased by $6.7-40.3 \%$ and $5.4-19.8 \%$, respectively. A similar trend was observed in total $\mathrm{Chl}$, which substantially increased under intercropping systems (Fig. 1C). Moreover, intercropping patterns significantly increased the ratio of Chl $a / b$ (Fig. 1D), and 2M4B treatment showed further improvements of $1.25,1.27$, and 1.20 during the flowering, filling, and maturity stages, respectively, compared with the SM treatment.

Chl fluorescence parameters are the standard parameters for evaluating leaf ripening and senescence. At the flowering stage, a slight difference was observed between the four intercropping patterns in terms of the $\mathrm{F}_{\mathrm{v}} / \mathrm{F}_{\mathrm{m}}, \Phi_{\text {PSII }}$, $\mathrm{q}_{\mathrm{L}}$, and NPQ (Table 3). However, at the maturity stage, the 2M4B treatment significantly increased the $\mathrm{F}_{\mathrm{v}} / \mathrm{F}_{\mathrm{m}}, \Phi_{\mathrm{PSII}}$, and $\mathrm{q}_{\mathrm{L}}$ values by $13.3,34.8$, and $41.5 \%$, respectively. By contrast, NPQ was decreased by $17.8 \%$ compared with that in the sole proso millet.

Antioxidant metabolism: The behavior of enzymes involved in antioxidant metabolism during the reproductive stage under intercropping treatments was studied. Significant differences were found in the leaf antioxidant metabolism between treatments, and the activities of SOD, POD, and CAT in the reproductive growth stage declined until maturity (Fig. 2). The SOD activity increased under intercropping patterns, which were 20.6-64.4\% and $12.9-52.7 \%$ higher than those of the conventional sole proso millet in 2017 and 2018, respectively (Fig. 2A). The activities of POD and CAT showed the same trend, i.e., increased by $18.1-41.7 \%$ and $14.7-48.2 \%$ for POD (Fig. 2B) and $17.5-42.1 \%$ and $14.2-45.7 \%$ for CAT (Fig. 2C) over two years, respectively.

ROS in the leaf was assayed, and the results indicated that MDA and $\mathrm{O}_{2}{ }^{-}$- were negatively affected by intercropping patterns, and decreased by $6.5-27.2 \%$ (Fig. $3 A$ ) and $13.6-30.9 \%$ (Fig. $3 B$ ) relative to the control, respectively. However, a different trend was observed for ASA contents (Fig. 3C) in which the values were higher than that in SM. The 2M4B treatment significantly improved the ASA contents of proso millet, which increased by $20.4,46.5$, and $73.1 \%$ at the three determined stages, respectively, compared with the conventional tillage (SM).

Physiological metabolism: The behavior of enzymes involved in physiological metabolism during the reproductive stage under intercropping treatments was studied. In 2017 and 2018, the average GS activity of the leaf was substantially elevated (Fig. $4 A$ ), and increased by $8.9,13.0,19.5$, and $30.7 \%$ under $2 \mathrm{M} 2 \mathrm{~B}, 4 \mathrm{M} 2 \mathrm{~B}, 4 \mathrm{M} 4 \mathrm{~B}$, and $2 \mathrm{M} 4 \mathrm{~B}$, respectively, compared with those in the sole 


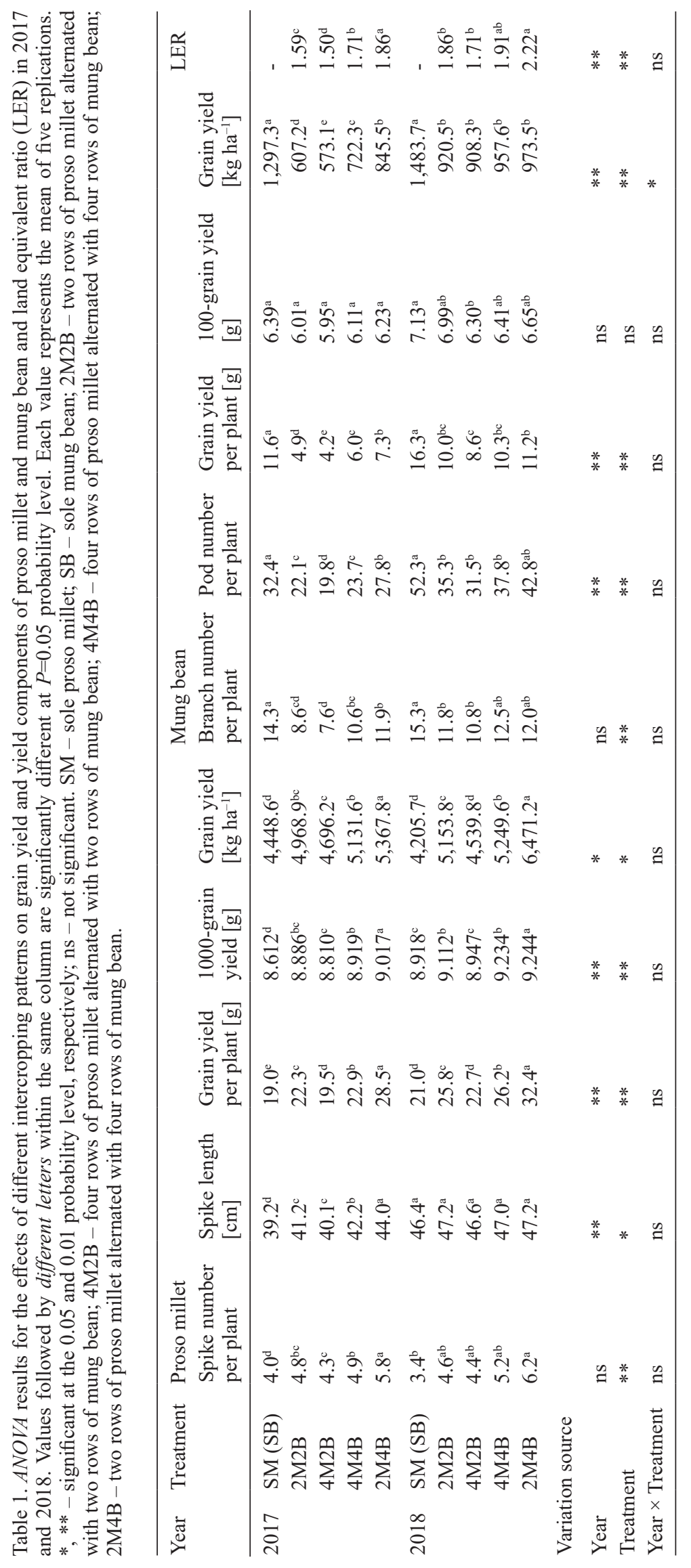


Table 2. ANOVA results for the effects of different intercropping patterns on plant senescence and biomass of proso millet at the filling stage in 2017 and 2018. Values followed by different letters within the same column are significantly different at $P=0.05$ probability level. Each value represents the mean of five replications. Yellow leaf rate is indicated by yellow leaf number per plant by total leaf number per plant. ${ }^{*}, * *$ - significant at the 0.05 and 0.01 probability level, respectively; ns - not significant. SM - sole proso millet; $2 \mathrm{M} 2 \mathrm{~B}$ - two rows of proso millet alternated with two rows of mung bean; 4M2B - four rows of proso millet alternated with two rows of mung bean; 4M4B - four rows of proso millet alternated with four rows of mung bean; 2M4B - two rows of proso millet alternated with four rows of mung bean.

\begin{tabular}{|c|c|c|c|c|c|c|c|c|}
\hline \multirow[t]{2}{*}{ Year } & \multirow[t]{2}{*}{ Treatment } & \multicolumn{3}{|l|}{ Plant senescence } & \multicolumn{4}{|c|}{ Biomass per plant $[\mathrm{g}]$} \\
\hline & & Leaf number per plant & Leaf area per plant $\left[\mathrm{mm}^{2}\right]$ & Yellow leaf rate [\%] & Stem & Leaf & Sheath & Spike \\
\hline \multirow[t]{5}{*}{2017} & SM & $27.6^{\mathrm{c}}$ & $1,488.3^{\mathrm{b}}$ & $33.7^{\mathrm{a}}$ & $21.6^{\mathrm{b}}$ & $7.3^{\mathrm{b}}$ & $3.36^{\mathrm{c}}$ & $12.4^{\mathrm{d}}$ \\
\hline & $2 \mathrm{M} 2 \mathrm{~B}$ & $35.0^{\mathrm{bc}}$ & $1,708.0^{\mathrm{b}}$ & $20.8^{\mathrm{ab}}$ & $31.5^{\mathrm{a}}$ & $11.4^{\mathrm{a}}$ & $5.26^{\mathrm{ab}}$ & $18.4^{\text {bc }}$ \\
\hline & $4 \mathrm{M} 2 \mathrm{~B}$ & $30.6^{\mathrm{bc}}$ & $1,560.4^{b}$ & $27.0^{\mathrm{ab}}$ & $24.2^{\mathrm{b}}$ & $8.7^{\mathrm{b}}$ & $4.45^{\mathrm{bc}}$ & $15.4^{\mathrm{cd}}$ \\
\hline & $4 \mathrm{M} 4 \mathrm{~B}$ & $36.8^{\mathrm{b}}$ & $1,829.4^{\mathrm{ab}}$ & $17.4^{\mathrm{b}}$ & $33.9^{\mathrm{a}}$ & $12.7^{\mathrm{a}}$ & $5.20^{\mathrm{ab}}$ & $21.5^{\mathrm{ab}}$ \\
\hline & 2M4B & $45.2^{\mathrm{a}}$ & $2,161.3^{\mathrm{a}}$ & $12.5^{\mathrm{b}}$ & $37.2^{\mathrm{a}}$ & $12.9^{\mathrm{a}}$ & $6.08^{\mathrm{a}}$ & $24.9^{\mathrm{a}}$ \\
\hline \multirow[t]{5}{*}{2018} & SM & $31.6^{\mathrm{b}}$ & $1,760.4^{\mathrm{a}}$ & $31.2^{\mathrm{a}}$ & $27.9^{\mathrm{b}}$ & $10.8^{\mathrm{b}}$ & $5.26^{\mathrm{c}}$ & $17.9^{\mathrm{b}}$ \\
\hline & 2M2B & $39.2^{\mathrm{b}}$ & $2,048.0^{\mathrm{a}}$ & $23.0^{\mathrm{ab}}$ & $36.3^{\mathrm{b}}$ & $13.1^{\mathrm{b}}$ & $6.36^{\mathrm{b}}$ & $21.1^{\mathrm{b}}$ \\
\hline & $4 \mathrm{M} 2 \mathrm{~B}$ & $34.6^{\mathrm{b}}$ & $1,828.3^{\mathrm{a}}$ & $25.5^{\mathrm{a}}$ & $30.6^{\mathrm{b}}$ & $11.3^{\mathrm{b}}$ & $6.21^{\mathrm{bc}}$ & $19.4^{\mathrm{b}}$ \\
\hline & 4M4B & $38.0^{\mathrm{b}}$ & $1,989.4^{\mathrm{a}}$ & $23.4^{\mathrm{ab}}$ & $32.2^{\mathrm{b}}$ & $11.1^{\mathrm{b}}$ & $6.71^{\mathrm{b}}$ & $25.8^{\mathrm{b}}$ \\
\hline & 2M4B & $51.2^{\mathrm{a}}$ & $2,441.3^{\mathrm{a}}$ & $10.3^{\mathrm{b}}$ & $59.3^{\mathrm{a}}$ & $16.2^{\mathrm{a}}$ & $8.17^{\mathrm{a}}$ & $35.7^{\mathrm{a}}$ \\
\hline \multicolumn{9}{|c|}{ Variation source } \\
\hline \multicolumn{2}{|l|}{ Year } & $*$ & $*$ & ns & $* *$ & $* *$ & $* *$ & $* *$ \\
\hline \multicolumn{2}{|c|}{ Treatment } & $* *$ & $* *$ & $* *$ & $* *$ & $* *$ & $* *$ & $* *$ \\
\hline \multicolumn{2}{|c|}{ Year $\times$ Treatment } & ns & ns & ns & $*$ & $* *$ & ns & ns \\
\hline
\end{tabular}

proso millet treatment. NR activity had values similar to the GS activity and intercropping patterns, which were significantly increased by $4.6-10.1 \%$ for 2017 and $5.1-$ $12.6 \%$ for 2018 compared with that of the sole proso millet treatment (Fig. 4B).

In addition, the average soluble protein content (Fig. 4C) was remarkably higher under intercropping patterns than that under the sole proso millet treatment, and increased by $21.0 \%$ for $2 \mathrm{M} 2 \mathrm{~B}, 16.6 \%$ for $4 \mathrm{M} 2 \mathrm{~B}, 24.1 \%$ for $4 \mathrm{M} 4 \mathrm{~B}$, and $27.3 \%$ for $2 \mathrm{M} 4 \mathrm{~B}$. Free amino acid content increased at different levels in the four intercropping treatments (Fig. 4D). At the maturity stage, the final free amino acid content of intercropping patterns increased by $9.2-45.0 \%$ in 2017 and $6.0-50.1 \%$ in 2018 compared with sole proso millet treatment.

Coefficients $(r)$ of significant correlations between yield and leaf physiological traits: Many leaf physiological traits were correlated, either positively or negatively, with the yield (Fig. 5). However, only four traits (NPQ, MDA, $\mathrm{O}_{2}^{--}$, and YLR) were natively correlated with yield. Among the four traits, YLR showed the highest correlation coefficients $(r=-0.878, P \leq 0.01)$, followed by $\mathrm{O}_{2}{ }^{-}(r=0.780, P \leq 0.01), \operatorname{MDA}(r=0.776, P \leq 0.01)$, and NPQ $(r=0.696, P \leq 0.05)$. Unlike the negative correlations, leaf Chl fluorescence parameters, such as $\mathrm{F}_{\mathrm{v}} / \mathrm{F}_{\mathrm{m}}, \mathrm{q}_{\mathrm{L}}, \mathrm{LN}$, and LA, were highly positively correlated to yield $(r=0.924,0.891$, 0.923 , and 0.862 , respectively). The leaf Chl showed a strong and positive correlation to yield $(r=0.829, P \leq 0.01)$, but Chl $a / b$ ratio had a weak correlation $(r=0.283)$.

\section{Discussion}

The intercropping of cereal crop with a legume is a preferred system for increasing food supply and reducing environmental feedback (Temesgen et al. 2015). Considering the mutual benefits that exist in cereal-legume intercropping, the system productivity is greatly promoted but has low input (Zhang et al. 2015). In the present study, intercropped proso millet with tall-statured niche showed increased leaf number and area and decreased yellow leaf rate at the later stages (Table 2). This condition may occur because the leaves are one of the main organs for supply assimilation, and that intercropped proso millet was developed with adequate space environment. These results suggested that intercropping would delay reproductive growth, thereby increasing leaf photosynthetic capacity. Generally, senescence is caused by an imbalance in the source/sink relationship, and the capacity of source leaf to capture carbohydrates improves storage capacity (Gerardeaux et al. 2010). Biomass, which can reflect the growth status of plants, can be affected by environmental conditions and planting patterns (Bhatt et al. 2007). Our results showed that dry matter accumulation increased by $95.1 \%$ in the stem, $60.8 \%$ in the leaf, $65.5 \%$ in the sheath, and $99.5 \%$ in the spike under 2M4B treatment (Table 2). This phenomenon may be associated with increased changes in morphology and increased leaf number and area under the sufficient illumination environment as a consequence of increased output; these findings are consistent with those in previous studies (Yin et al. 2017). In addition, crop yield 


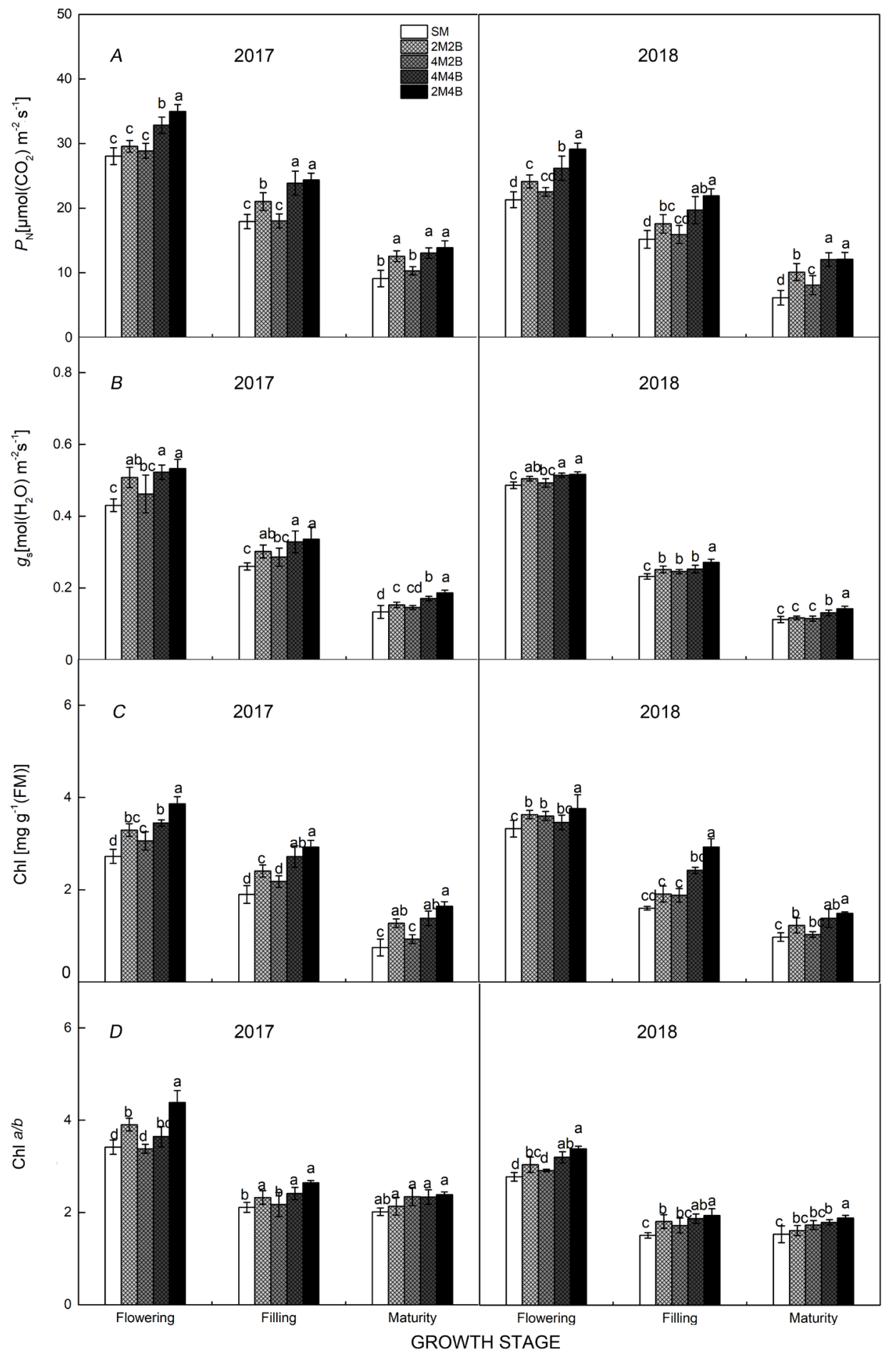

Fig. 1. Changes of net photosynthetic rate $\left(P_{\mathrm{N}}\right)(A)$, stomatal conductance $\left(g_{\mathrm{s}}\right)(B)$, chlorophyll content $(C)$, and chlorophyll $a / b(D)$ of proso millet under different intercropping patterns in 2017 and 2018. Each value represents the mean of five replications \pm SE. The columns followed by different letters are significantly different at $P=0.05$ level. SM - sole proso millet; $2 \mathrm{M} 2 \mathrm{~B}$ - two rows of proso millet alternated with two rows of mung bean; $4 \mathrm{M} 2 \mathrm{~B}$ - four rows of proso millet alternated with two rows of mung bean; 4M4B - four rows of proso millet alternated with four rows of mung bean; M4B - two rows of proso millet alternated with four rows of mung bean.

is a biological index at the population level that reflects the total reproductive output of all individuals per unit area. In this study, the average yield was $6.8-37.3 \%$, which was higher than that in the sole proso millet treatment (Table 1).
Meanwhile, the LER for the different intercropping patterns was all greater than unity $(>1)$, despite that the grain yield of mung bean decreased, suggesting that proso millet intercropped with mung bean would boost the 


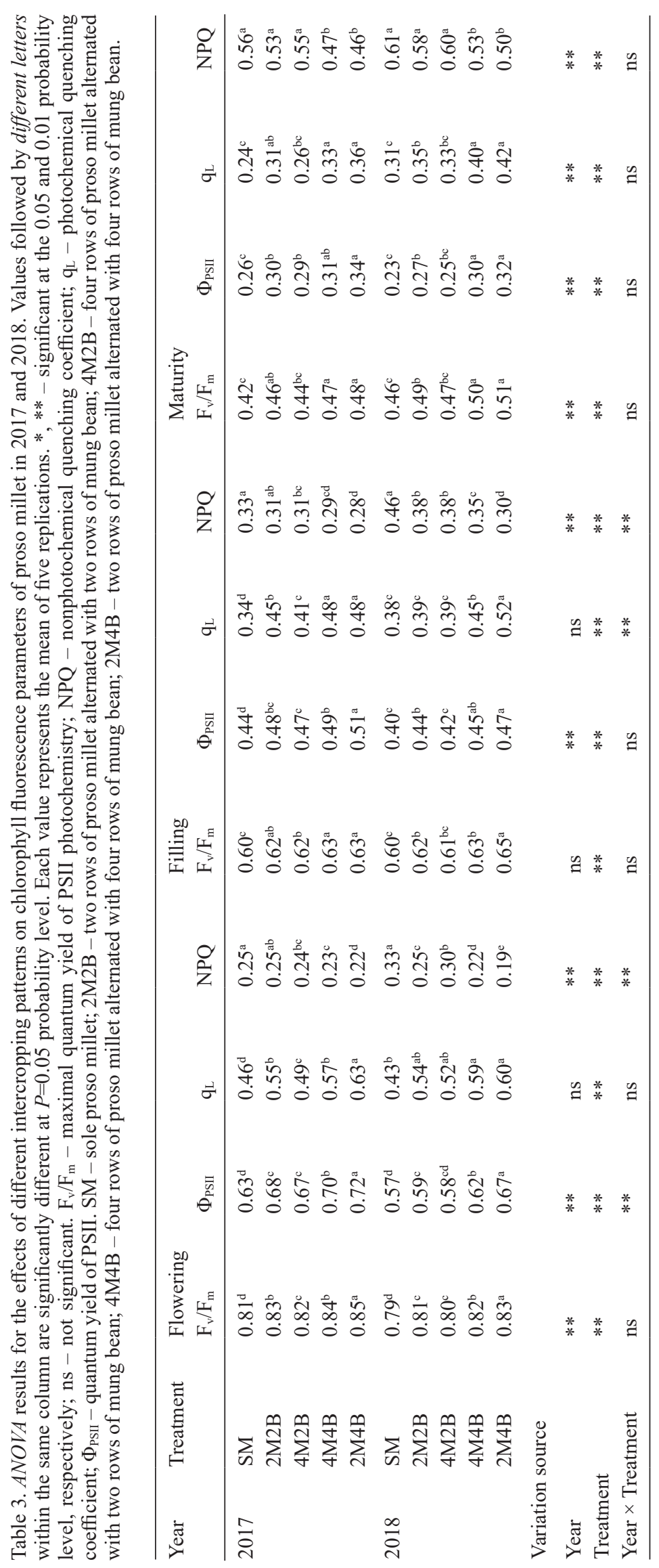




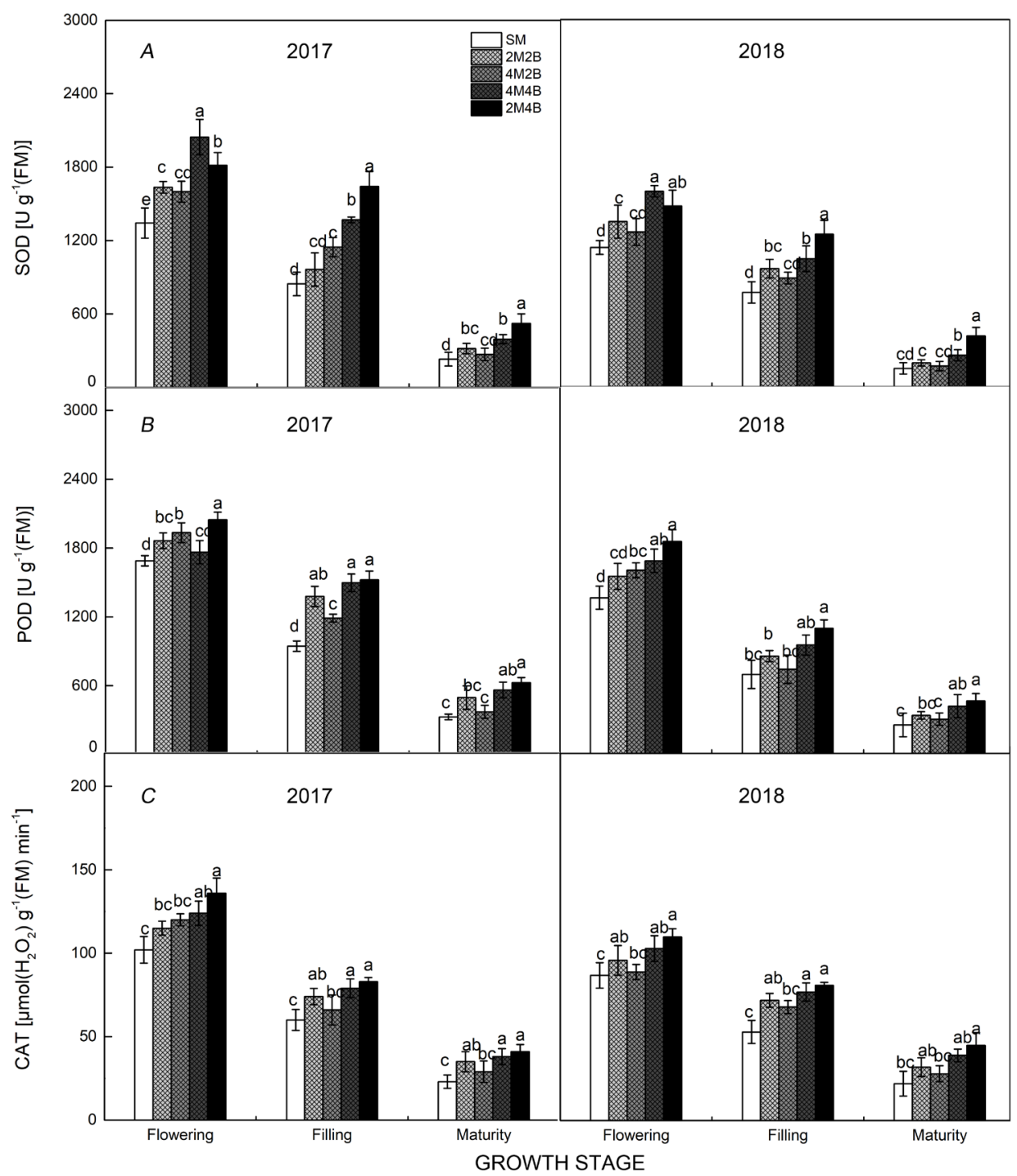

Fig. 2. Changes of superoxide dismutase (SOD) $(A)$, peroxidase (POD) $(B)$, and catalase (CAT) $(C)$ activities of proso millet under different intercropping patterns in 2017 and 2018. Each value represents the mean of five replications \pm SE. The columns followed by different letters are significantly different at $P=0.05$ level. $\mathrm{SM}$ - sole proso millet; $2 \mathrm{M} 2 \mathrm{~B}$ - two rows of proso millet alternated with two rows of mung bean; 4M2B - four rows of proso millet alternated with two rows of mung bean; 4M4B - four rows of proso millet alternated with four rows of mung bean; $2 \mathrm{M} 4 \mathrm{~B}$ - two rows of proso millet alternated with four rows of mung bean.

system productivity. Similar results were found by $\mathrm{Hu}$ et al. (2016).

The improvement of plant growth under the external environment is often associated with physiological metabolism (Moradi and Ismail 2007, Naeem et al. 2010). Photosynthetic capacity can be determined through gas exchange, and $\mathrm{Chl}$ fluorescence measurements provide a good way to assess the effects of environment on plants and to gain insight into the behavior of photosynthetic machinery (Farquhar and Sharkey 1982, Ren et al. 2016). In our study, intercropping induced the increase in $P_{\mathrm{N}}$ accompanied by a pronounced increase in $g_{\mathrm{s}}$, Chl content, and Chl $a / b$ (Fig. 1). This finding was consistent with the results of Gong et al. (2015), who illustrated that intercropping could create enough photosynthetic potential and enhance leaf carbon metabolism and assimilation to regulate leaf senescence. In fact, damage in chloroplast membrane occurs early during leaf senescence (Guo and Gan 2005). Chl degradation is the first visible symptom of senescence, but by the time leaf yellowing is visible, majority of the senescence process has occurred (He et al. 2002). Fritschi and Ray (2007) reported that the relative proportion of $\mathrm{Chl}$ associated with the PSI complex and PSII core reaction center complex decreases with reduced $\mathrm{Chl} a / b$ ratio. Moreover, photon energy in PSII is closely related to premature ageing (Jiao et al. 2003, Bron et al. 2004). Accordingly, lower $\mathrm{F}_{\mathrm{v}} / \mathrm{F}_{\mathrm{m}}$ and PSII in the SM treatment (Table 3) indicated that photon energy conversion and electron transfer increased in proso millet leaf under intercropping patterns. Additionally, $\mathrm{q}_{\mathrm{L}}$ was higher in the 2M4B treatment, but NPQ showed the opposite trend, which was a decrease by $17.8 \%$ compared 


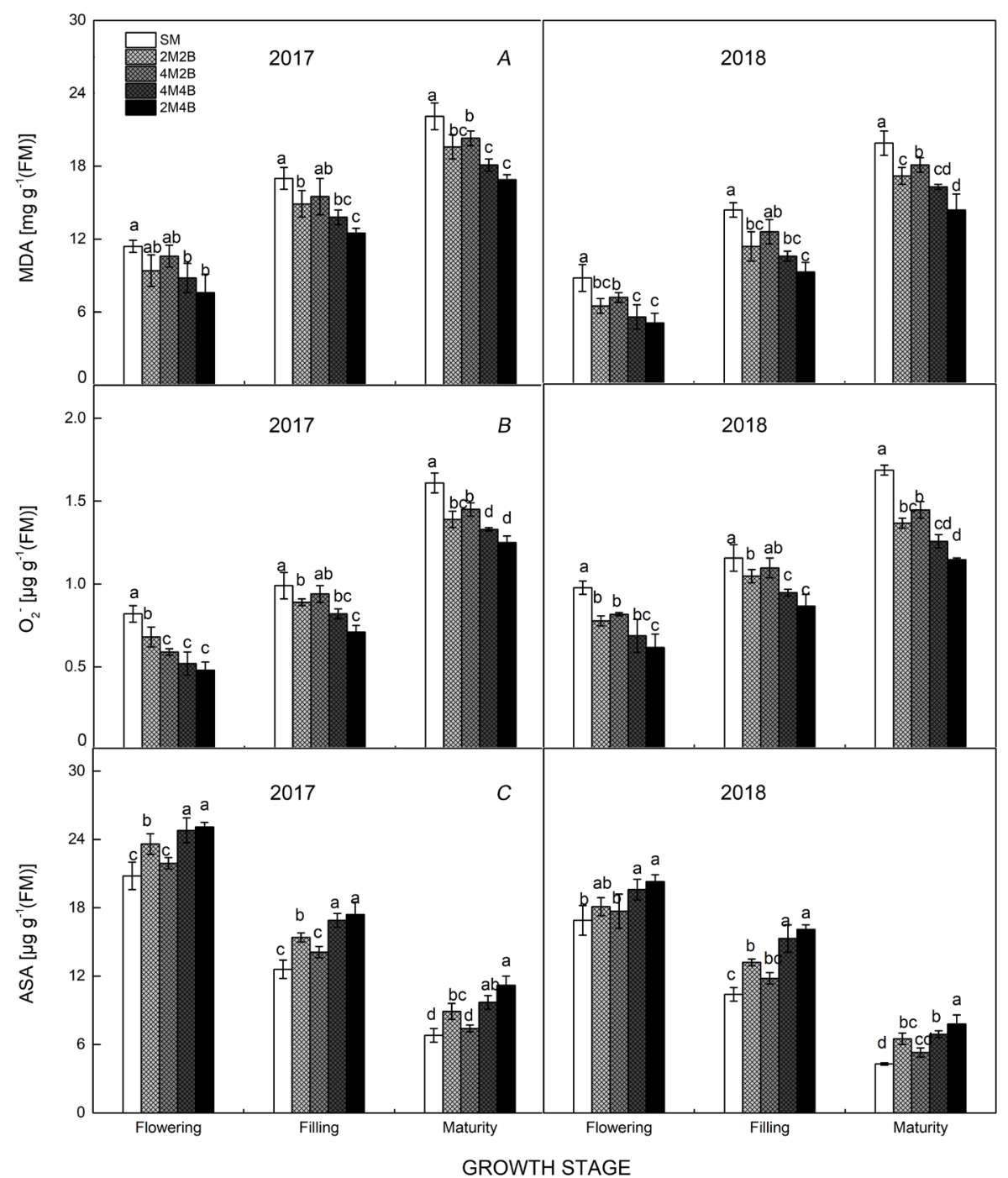

Fig. 3. Changes of malondialdehyde (MDA) $(A)$, superoxide radicals $\left(\mathrm{O}_{2}{ }^{-}\right)(B)$, and ascorbate (ASA) $(C)$ contents of proso millet under different intercropping patterns in 2017 and 2018. Each value represents the mean of five replications \pm SE. The columns followed by different letters are significantly different at $P=0.05$ level. $\mathrm{SM}$ - sole proso millet; $2 \mathrm{M} 2 \mathrm{~B}$ - two rows of proso millet alternated with two rows of mung bean; $4 \mathrm{M} 2 \mathrm{~B}$ - four rows of proso millet alternated with two rows of mung bean; 4M4B - four rows of proso millet alternated with four rows of mung bean; $2 \mathrm{M} 4 \mathrm{~B}$ - two rows of proso millet alternated with four rows of mung bean.

with the sole proso millet treatment at maturity (Table 3). These results are in good agreement with a previous work on maize plants where nitrogen supply increased photosynthetic activity and delayed the leaf senescence (Lima et al. 1999, Kitonyo et al. 2018). These findings suggested that intercropping treatment is important in delaying the progress of proso millet leaf senescence, and increases the activities of photosynthetic reaction centers and improves electron transfer quantum efficiency of PSII and excess light energy utilization, which might decrease excess energy dissipation as heat.

Generally, the inhibition of physiological metabolism and photosynthesis is mainly attributed to the membrane lipid peroxidation and leaf ageing acceleration induced by the damaged antioxidant system under abiotic stresses. ROS-scavenging system plays an important role in protecting cells from photooxidative damage and may be an index to evaluate the leaf senescence when plants cannot move far from their unfavorable environment. Certainly, the antioxidant system in plants enhances the resistance to membrane peroxidation secondary to ROS under suitable external conditions. Chen et al. (2018) reported that the ridge-covered mulching plastic film remarkably increased the activities of POD, CAT, and SOD in maize leaves at the grain-filling stage, thus weakening lipid peroxidation and eventually delaying senescence and improving maize productivity. Our results showed that intercropping significantly increased the activities of SOD (Fig. 2A), POD (Fig. 2B), and CAT (Fig. 2C), especially, under the 2M4B treatment, and were 58.6, 45.0, and 43.9\% higher, respectively, than those in the sole proso millet treatment. This condition could eliminate the damage from ROS due to lower MDA (Fig. $3 A$ ) and $\mathrm{O}_{2}^{-{ }^{-}}$(Fig. $3 B$ ) contents. These results indicated that intercropping patterns improved the 


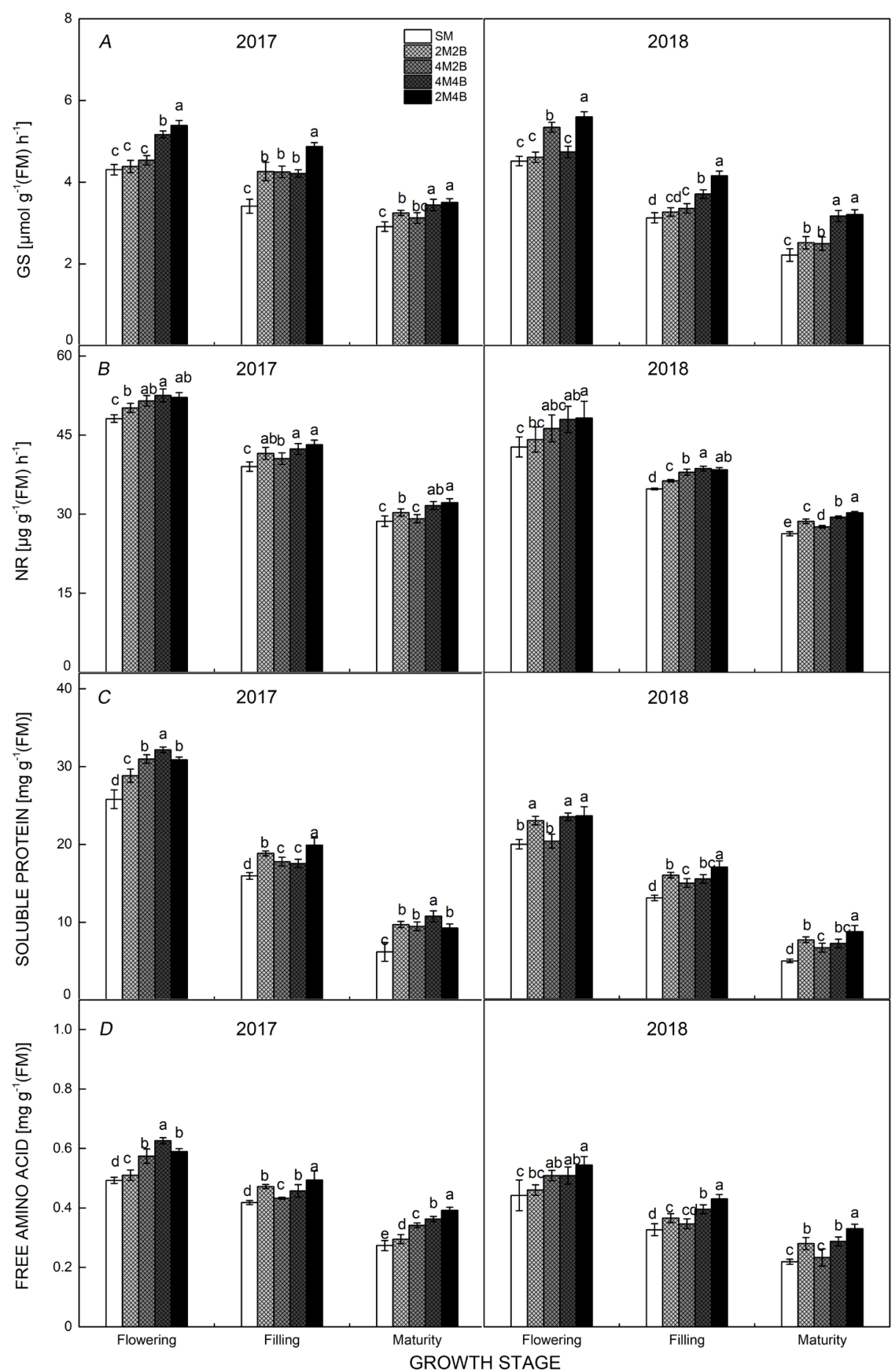

Fig. 4. Changes of glutamine synthetase (GS) $(A)$ and nitrate reductase (NR) $(B)$ activities, soluble protein $(C)$, and free amino acid $(D)$ contents of proso millet under different intercropping patterns in 2017 and 2018. Each value represents the mean of five replications $\pm \mathrm{SE}$. The columns followed by different letters are significantly different at $P=0.05$ level. SM - sole proso millet; $2 \mathrm{M} 2 \mathrm{~B}-$ two rows of proso millet alternated with two rows of mung bean; 4M2B - four rows of proso millet alternated with two rows of mung bean; 4M4B - four rows of proso millet alternated with four rows of mung bean; 2M4B - two rows of proso millet alternated with four rows of mung bean.

protective enzyme systems, thus enhancing the ability of scavenging ROS by reducing the ROS production and limiting membrane lipid peroxidation and membrane deterioration, thereby developing an advantageous direction that delays leaf senescence.

Leaf senescence is also highly dependent on $\mathrm{N}$ metabolism, because photosynthesis requires a large amount of $\mathrm{N}$ for the incorporation of $\mathrm{CO}_{2}$ and water into 


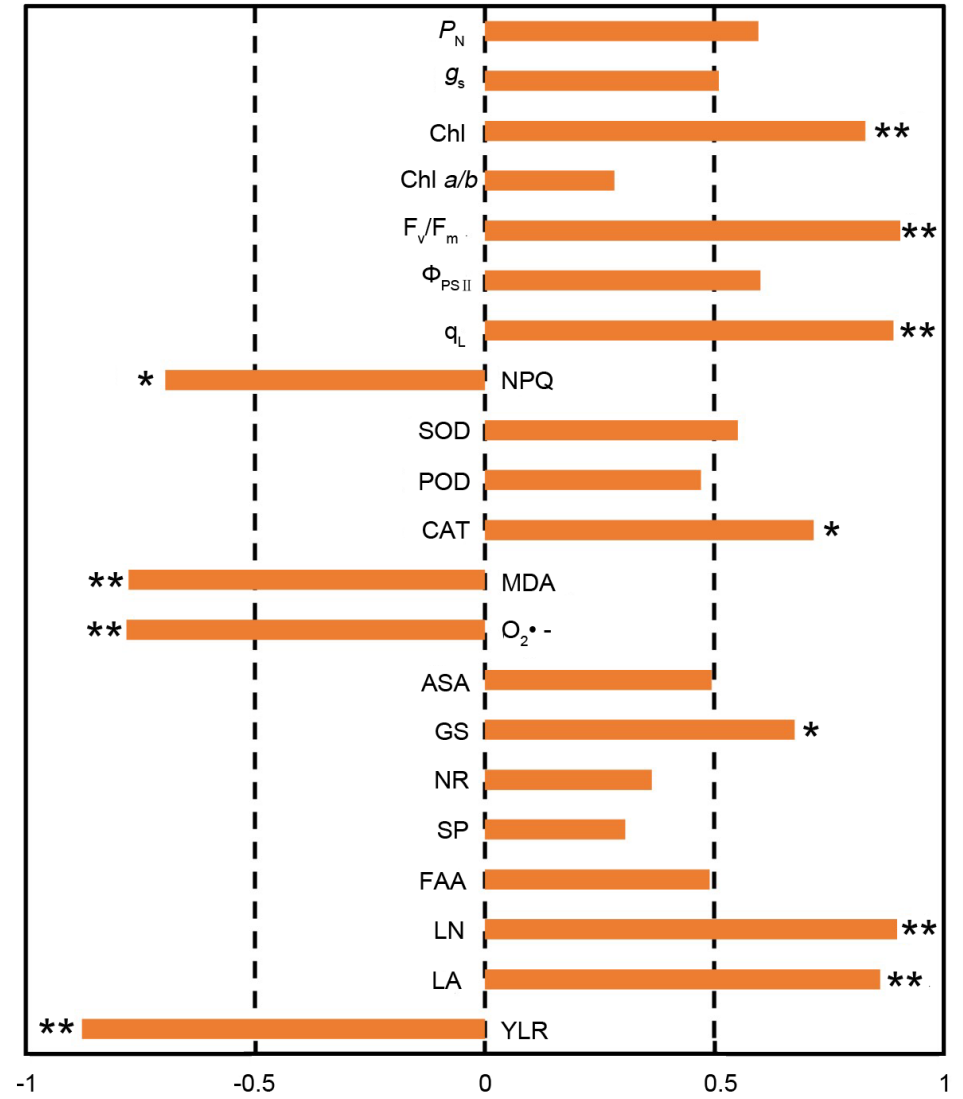

Fig. 5. Coefficients $(r)$ of the significant correlations between leaf physiological traits and yield. *,** significant at the 0.05 and 0.01 probability level, respectively. ASA - reduced ascorbic acid; CAT catalase; Chl - chlorophyll; FAA - free amino acid; $\mathrm{F}_{\mathrm{v}} / \mathrm{F}_{\mathrm{m}}$ - maximal quantum yield of PSII photochemistry; $g_{\mathrm{s}}$ - stomatal conductance; GS - glutamine synthetase; LA - leaf area; LN - leaf number; MDA malondialdehyde; NPQ - nonphotochemical quenching coefficient; $\mathrm{NR}$ - nitrate reductase; $\mathrm{O}_{2}{ }^{--}-$superoxide radical; $P_{\mathrm{N}}-$ net photosynthetic rate; $\mathrm{POD}$ - peroxidase; $\mathrm{q}_{\mathrm{L}}-$ photochemical quenching coefficient; SOD superoxide dismutase; SP - soluble protein; YLR yellow leaf rate; $\Phi_{\mathrm{PSII}}-$ quantum yield of PSII. sugars, which are relative to the Chl contents (Wang et al. 2015). Bi et al. (2017) reported that $\mathrm{N}$ metabolism may be associated with $\mathrm{Chl}$ synthesis and showed consistent results with leaf senescence in rice. Hence, $\mathrm{N}$ metabolism can also be a key reference to reflect the senescence in plant leaves. In the present study, the activities of GS (Fig. 4A) and NR (Fig. 4B) and the contents of soluble proteins and free amino acids in the flag leaves of intercropped proso millet were remarkably higher than those in the sole proso millet treatment at the late stage. This finding indicated that intercropped proso millet has a strong $\mathrm{N}$ assimilation and $\mathrm{NH}_{4}{ }^{+}$transport capacities, which increased the export of assimilates from the source to reproductive organs, and contribute to plant growth. Moreover, intercropping could delay leaf senescence and obtain high yield from the direction of physiological metabolism (Fig. 5).

Conclusions: Senescence of proso millet flag leaves varied substantially under different intercropping treatments. Optimizing the intercropping pattern increased the leaf number and area and decreased the yellow leaf rate. The grain yield of proso millet was improved by $6.8-37.3 \%$ compared with the sole proso millet treatment. These responses were the result of intercropping effects on leaf photosynthesis in terms of increased $P_{\mathrm{N}}, g_{\mathrm{s}}, \mathrm{Chl}$, and $\mathrm{Chl} a / b$, and positive changes in Chl fluorescence. Moreover, such improvements were due to the high activities of protective enzymes (SOD, CAT, and POD) and low MDA and $\mathrm{O}_{2}^{--}$contents in flag leaves, thus delaying leaf senescence under intercropping patterns.
This conclusion was evidenced by the strong nitrogen metabolism in leaves. Intercropping patterns, especially 2M4B, were optimal to delay the proso millet flag leaf senescence and increase grain yield in this region.

\section{References}

Ali S., Xu Y., Jia Q. et al: Ridge-furrow mulched with plastic film improves the anti-oxidative defence system and photosynthesis in leaves of winter wheat under deficit irrigation. PLoS ONE 13: e0200277, 2018.

Bhatt R.K., Baig M.J., Tiwari H.S.: Growth, biomass production, and assimilatory characters in Cenchrus ciliaris L. under elevated $\mathrm{CO}_{2}$ condition. - Photosynthetica 45: 296-298, 2007.

Bi Z., Zhang Y., Wu W. et al: ES7, encoding a ferredoxindependent glutamate synthase, functions in nitrogen metabolism and impacts leaf senescence in rice. - Plant Sci. 259: 24-34, 2017.

Bradford M.M.: A rapid and sensitive method for the quantitation of microgram quantities of protein utilizing the principle of protein-dye binding. - Anal. Biochem. 72: 248-254, 1976.

Bron I.U., Ribeiro R.V., Azzolini M. et al: Chlorophyll fluorescence as a tool to evaluate the ripening of 'Golden' papaya fruit. - Postharvest Biol. Tec. 33: 163-173, 2004.

Chen K., Ali S., Chen Y. et al: Effect of ridge-covering mulching materials on hormonal changes, antioxidative enzyme activities and production of maize in semi-arid regions of China. - Agr. Water. Manage. 204: 281-291, 2018.

Ding Y., Luo W., Xu G.: Characterisation of magnesium nutrition and interaction of magnesium and potassium in rice. - Ann. Appl. Biol. 149: 111-123, 2006.

Djanaguiraman M., Sheeba J.A., Durga D.D., Bangarusamy U.: 
Cotton leaf senescence can be delayed by nitrophenolate spray through enhanced antioxidant defence system. J. Agron. Crop Sci. 195: 213-224, 2009.

Elstner E.F., Heupel A.: Inhibition of nitrite formation from hydroxylammoniumchloride: A simple assay for superoxide dismutase. - Anal. Biochem.70: 616-620, 1976.

Fang Y., Xiong L.: General mechanisms of drought response and their application in drought resistance improvement in plants. Cell Mol. Life Sci. 72: 673-689, 2015.

Fang Z., Bouwkamp J.C., Solomos T.: Chlorophyllase activities and chlorophyll degradation during leaf senescence in nonyellowing mutant and wild type of Phaseolus vulgaris L. J. Exp. Bot. 49: 503-510, 1998.

Farquhar G. D., Sharkey T. D.: Stomatal conductance and photosynthesis. - Ann. Rev. Plant Physio. 33: 317-345, 1982.

Feller U., Anders I., Mae T.: Rubiscolytics: fate of rubisco after its enzymatic function in a cell is terminated. - J. Exp. Bot. 59: 1615-1624, 2008.

Frank V.B., Dat J.F.: Reactive oxygen species in plant cell death.Plant Physiol. 141: 384-390, 2006.

Fritschi F.B., Ray J.D.: Soybean leaf nitrogen, chlorophyll content, and chlorophyll $a / b$ ratio. - Photosynthetica 45: 92-98, 2007.

Gerardeaux E., Jordan-Meille L., Constantin J. et al: Changes in plant morphology and dry matter partitioning caused by potassium deficiency in Gossypium hirsutum (L.). - Environ. Exp. Bot. 67: 451-459, 2010.

Gill S.S., Tuteja N.: Reactive oxygen species and antioxidant machinery in abiotic stress tolerance in crop plants. - Plant Physiol. Bioch. 48: 909-930, 2010.

Gong W.Z., Jiang C.D., Wu Y.S. et al: Tolerance vs. avoidance: two strategies of soybean (Glycine max) seedlings in response to shade in intercropping. - Photosynthetica 53: 259-268, 2015.

Guo Y., Gan S.: Leaf senescence: signals, execution, and regulation. - Curr. Top. Dev. Biol. 71: 83-112, 2005.

He Y.H., Fukushige H., Hildebrand D.F., Gan S.S.: Evidence supporting a role of jasmonic acid in Arabidopsis leaf senescence. - Plant Physiol. 128: 876-884, 2002.

Hodges D.M., Andrews C.J., Johnson D.A., Hamilton R.I.: Antioxidant compound responses to chilling stress in differentially sensitive inbred maize lines. - J. Exp. Bot. 98: 685-692, 1996.

Hu F., Gan Y., Chai Q. et al: Boosting system productivity through the improved coordination of interspecific competition in maize/pea strip intercropping. - Field Crop. Res. 198: 50-60, 2016.

Hu W., Loka D.A., Fitzsimons T.R. et al: Potassium deficiency limits reproductive success by altering carbohydrate and protein balances in cotton (Gossypium hirsutum L.). Environ. Exp. Bot. 145: 87-94, 2018.

Inal A., Gunes A., Zhang F., Cakmak I.: Peanut/maize intercropping induced changes in rhizosphere and nutrient concentrations in shoots. - Plant Physiol. Bioch. 45: 350-356, 2007.

Jiang D., Dai T., Jing Q. et al: Effects of long-term fertilization on leaf photosynthetic characteristics and grain yield in winter wheat. - Photosynthetica 42: 439-446, 2004.

Jiao D., Ji B., Li X.: Characteristics of chlorophyll fluorescence and membrane-lipid peroxidation during senescence of flag leaf in different cultivars of rice. - Photosynthetica 41: 33-41, 2003.

Kaiser J.J., Lewis O.A.M.: Nitrate reductase and glutamine synthetase activity in leaves and roots of nitrate-fed Helianthus annuus L. - Plant Soil. 77: 127-130, 1984.

Khatun S., Ali M.B., Hahn E.J., Peak K.Y.: Copper toxicity in Withania somnifera: Growth and antioxidant enzymes responses of in vitro grown plants. - Environ. Exp. Bot. 64: 279-285, 2008.

Kitonyo O.M., Sadras V.O., Zhou Y., Denton M.D.: Nitrogen supply and sink demand modulate the patterns of leaf senescence in maize. - Field Crop. Res. 225: 92-103, 2018.

Lei Y., Yin C., Li C.: Differences in some morphological, physiological, and biochemical responses to drought stress in two contrasting populations of Populus przewalskii. Physiol. Plantarum 127: 182-191, 2006.

Li L., Yang S., Li X. et al: Interspecific complementary and competitive interactions between intercropped maize and faba bean. - Plant Soil 212: 105-114, 1999.

Lichtenthaler H.K.: Chlorophylls and carotenoids: pigments of photosynthetic biomembranes. - Method. Enzymol. 148: 350-382, 1987.

Lima J.D., Mosquim P.R., Da Matta F.M.: Leaf gas exchange and chlorophyll fluorescence parameters in Phaseolus vulgaris as affected by nitrogen and phosphorus deficiency. Photosynthetica 37: 113-121, 1999.

Lin C.C., Kao C.H.: $\mathrm{NaCl}$ induced changes in ionically bound peroxidase activity in roots of rice seedlings. - Plant Soil 216: 147-153, 1999.

Liu X., Rahman T., Song C. et al: Changes in light environment, morphology, growth and yield of soybean in maize-soybean intercropping systems. - Field Crop. Res. 200: 38-46, 2017.

Maxwell K., Johnson G.N.: Chlorophyll fluorescence a practical guide. - J. Exp. Bot. 51: 659-668, 2000.

Moradi F., Ismail A.M.: Responses of photosynthesis, chlorophyll fluorescence and ROS-scavenging systems to salt stress during seedling and reproductive stages in rice. - Ann. Bot.London 99: 1161-1173, 2007.

Naeem M.S., Jin Z.L., Wan G.L. et al: 5-Aminolevulinic acid improves photosynthetic gas exchange capacity and ion uptake under salinity stress in oilseed rape (Brassica napus L.). Plant Soil 332: 405-415, 2010.

Naudin C., van der Werf H.M.G., Jeuffroy M.H., Corre-Hellou G.: Life cycle assessment applied to pea-wheat intercrops: A new method for handling the impacts of co-products. - J. Clean. Prod. 73: 80-87, 2014.

Navabpour S., Morris K., Allen R. et al: Expression of senescence - enhanced genes in response to oxidative stress. - J. Exp. Bot. 54: 2285-2292, 2003.

Ren B., Zhang J., Dong S. et al: Effects of waterlogging on leaf mesophyll cell ultrastructure and photosynthetic characteristics of summer maize. - PLoS ONE 11: e0161424, 2016.

Ren B., Zhang J., Dong S. et al: Exogenous 6-benzyladenine improves antioxidative system and carbon metabolism of summer maize waterlogged in the field. - J. Agron. Crop Sci. 204: 175-184, 2018.

Špundová M., Slouková K., Hunková M., Nauš J.: Plant shading increases lipid peroxidation and intensifies senescenceinduced changes in photosynthesis and activities of ascorbate peroxidase and glutathione reductase in wheat. Photosynthetica 43: 403-409, 2005.

Temesgen A., Shu F., Rodriguez D.: As the level of crop productivity increases: Is there a role for intercropping in smallholder agriculture. - Field Crop. Res. 180: 155-166, 2015.

Wang Z., Lu J., Yang M. et al: Stoichiometric characteristics of carbon, nitrogen, and phosphorus in leaves of differently aged lucerne (Medicago sativa) stands. - Front. Plant Sci. 6: 1062, 2015.

Willey R.W.: Intercropping: its importance and research needs. I. Competition and yield advantages. - Field Crop Abstracts 32: 
73-85, 1979.

Yang Q., Zhang P., Qu Y. et al: Comparison of physicochemical properties and cooking edibility of waxy and non-waxy proso millet (Panicum miliaceum L.). - Food Chem. 257: 271-278, 2018.

Yin W., Chen G., Feng F. et al: Straw retention combined with plastic mulching improves compensation of intercropped maize in arid environment. - Field Crop. Res. 204: 42-51, 2017.

Zhang H., Zhou C.: Signal transduction in leaf senescence. Plant Mol. Biol. 82: 539-545, 2013.
Zhang N.N., Sun Y.M., Wang E.T. et al: Effects of intercropping and Rhizobial inoculation on the ammonia-oxidizing microorganisms in rhizospheres of maize and faba bean plants. - Appl. Soil. Ecol. 85: 76-85, 2015.

Zhang Y., Han H., Zhang D. et al: Effects of ridging and mulching combined practices on proso millet growth and yield in semiarid regions of China. - Field Crop. Res. 213: 65-74, 2017.

Zhao J.Q., Zhao F.Q., Jian G.L. et al: Intensified Alternaria spot disease under potassium deficiency conditions results in acceleration of cotton (Gossypium hirsutum L.) leaf senescence. - Aust. J. Crop. Sci. 7: 241-248, 2013.

(c) The authors. This is an open access article distributed under the terms of the Creative Commons BY-NC-ND Licence. 